\title{
International Symposium "Forest soils under global and local changes" Bordeaux, 15-18 September 2004
}

Under the auspices of the International Union of Soil Sciences (IUSS) and International Union of Forest Research Organization (IUFRO), 100 scientists representing 20 countries, 37 universities and 15 research institutes attended in September 2004 a four-day international symposium "Forest soils under global and local changes: from research to practice" in Bordeaux, France. The symposium was co-organized by IEFC (European Institute of Cultivated Forests), INRA (National Institute of Agronomic Research) and ENITAB (National School of Agricultural Engineers of Bordeaux). There were seven plenary sessions and the papers published in this issue were presented in three sessions.

- The article on potential for increase in $\mathrm{CO} 2$ flux from forest soils in Japan (Ishizuka et al.) was presented in session 1 on Carbon and Greenhouse Gases. This session provided an update and deep insights into the issues of $\mathrm{C}$ sinks and fluxes from forest soils. As illustrated by this article, main items of interest in this session included the spatial and temporal changes due to high variability at the local and regional scales and the need to combine information from soil surveys with forest management in the context of the whole system (soil-climate-forest practices). New attempts of modelling $\mathrm{C}$ fluxes were presented taking into account abiotic (temperature and moisture) and biotic (vegetation species) factors. Research results on $\mathrm{C}$ pools in forest ecosystems and their spatial and temporal variation were provided including dynamics of $\mathrm{C}$ in biomass components and in the forest soil. Development of methodologies for soil respiration and soil CO2 concentrations measurements were also presented.

- The article on diversity of wood decomposer communities in different forest stands (Kulhankova et al.) was presented in session 2 on Soil Biology. Presentations in this session covered the nature and extent of changes in soil biota and their activity under future global change scenarios and under land use and management changes. The role of forest soils as habitat for diverse organisms and the potential effects of management and global change on soil function though habitat modification were discussed during the session with case studies presentations. The article illustrates and compares the dynamics of colonization of similar dead wood sample by decomposer communities in a native forest and in four single-species forest plantations.

- The article on Carbon and Nutrient stocks in mature Quercus robur stand in Spain (Balboa et al.) was presented in session 3 on Productivity and Nutrition. Many examples and posters from various regions of the world were provided during that session; they gave insights into nutrient balance, nutrient cycling capacity and nutritional constraints from forest systems ranging from high-yielding eucalypt plantations in Brazil where soil texture is an important indicator of soil quality to pedunculate oak stands and extensive holm oak forest areas in Spain which are subjected to severe degradation as a consequence of poor management and fire damage. The session was concluded with a presentation of results from coniferous forest ecosystems subjected to experimental manipulation involving altered nitrogen deposition, emphasising the need, in forest research, for projects of longer duration than conventionally programmed by funding agencies.

Other sessions of the symposium included (4) Sustainable Forest and Soil Management, (5) hydrological cycles, (6),Disturbances and site restoration, and (7) Residues recycling in forests. 